\title{
Pros and cons of infrared thermography for veterinary science and industry
}

\section{Editorial}

This editorial seeks to appraise the most critical pros and cons of Infrared thermography (IRT) as a promising technology for veterinary science and industry. This technology has the capability to detect thermal radiations from any surface of any object. ${ }^{1}$ What makes IRT special is its noninvasive and noncontact nature. Changes in skin temperature, indicating metabolic changes in underlying tissues, may be monitored by this technology. ${ }^{2,3}$ The temperature would depend on blood flow and tissue metabolism rate. ${ }^{4}$ Thus, the IRT could potentially examine and quantify physiology and health through monitoring overlying skin temperature changes. ${ }^{5}$ As such, the IRT may help diagnose and more importantly to prognose inflammation related to metabolic disorders such as laminitis and mastitis. ${ }^{6-11}$

In a nutshell, the IRT may aid in early diagnosis of the many health issues on farm before the occurrence of distressing economical consequences. This would mean a prognostic capability for IRT in modern veterinary science and industry. Such a capability would allow interventions to prevent and attenuate unhealthy conditions. Nevertheless, any solid and reliable use will yet need to be realized on a global scale. This requires more extensive and longitudinal studies to enable decision-making on the stage and severity of forthcoming health challenges.

In working with infrared cameras, it is crucial to remove any outlier maximum temperatures of extraneous and unrepresentative particles. In addition, depending on the surface of interest, a control skin area ought to be traced for within-area and within-animal corrections. The maximum relative temperature of the control area must be deducted from that of the target surface to minimize variability and allow interanimal comparisons. ${ }^{4}$

The IRT is a noninvasive technology and on-farm tool that imposes minimal stress to the animal. This is of interest from an animal welfare perspective. ${ }^{12}$ Effective education for on-farm application of IRT will provide means to weigh advantages against disadvantages for future investments. The high cost could be a limiting factor that must be dealt with through interdisciplinary research and education. Moreover, the ability of IRT in forecasting clinical problems long before symptoms occur remains unestablished. Artifacts are of concern as well. The unreal values result from the several interfering factors affecting thermal radiations detected. The thermal radiation coming from the surface of interest (and not from the environment) must be specified and quantified. Furthermore, although IRT monitors skin temperature changes, it provides inadequate information on possible causes. This implies the necessity of applying parallel management tools and strategies for optimally accurate measurements, successful prevention, and effective treatments.

To conclude, pros and cons of IRT must be well studied, quantified, and weighed before the technology can be feasibly and economically recommended on-farm. It is mainly a prognostic capability for IRT that could justify large investments and attract global merit for future applications in animal industries.
Volume I Issue 3 - 2014

\author{
Akbar Nikkhah \\ Department of Animal Sciences, University of Zanjan, Iran
}

Correspondence: Akbar Nikkhah, Chief Highly Distinguished Professor, Department of Animal Sciences, Faculty of Agricultural Sciences, University of Zanjan, Iran, National Elite Foundation, Iran. Tel +98 243305 280I, Fax +98 2433053202 , Email anikkha@yahoo.com

Received: December 03, 2014 | Published: December 04, 2014

\section{Acknowledgments}

Thanks to the Iran's Ministry of Science Research \& Technology, National Elite Foundation, and University of Zanjan for supporting the author's global programs of optimizing the third millennium science education.

\section{Conflict of interest}

Author declares that there is no conflict of interest.

\section{References}

1. Nikkhah A, H Safari. Infrared thermography to timely diagnose, prevent and monitor equine laminitis. Proceedings of First National Congress on Pure Persian Horses, Tehran, Iran; 2012. p. 230-234,

2. Nikkhah A, H Safari. Infrared thermography to optimize equine health physiology and management. Proceedings of First National Congress on Pure Persian Horses, Tehran, Iran; 2012. p. 235-241,

3. Nikkhah A, H Safari. Infrared thermography for effective diseases prevention and management and welfared poultry production. Proceedings of the 2nd Scientific \& Specialized Conference on Iranian Poultry Industry. Qom, Iran; 2013.

4. Nikkhah A, Plaizier JC, Einarson MS, et al. Infrared thermography and visual examination of hooves of dairy cows in two stages of lactation. $J$ Dairy Sci. 2005;88(8):2749-2753.

5. Nikkhah A, H Safari. Infrared thermography capability in effective laminitis prevention and management in dairy cows. The 8th Convention of Iranian Veterinary Clinicians \& the 2nd Symposium on Ruminant Lameness and its Economical Significance on Animal Products. University of Shiraz, Shiraz, Iran; 2013.

6. Nikkhah A, H Safari. Infrared thermography technology: Economical management of modern animal industries. The 8th Convention of Iranian Veterinary Clinicians \& the 2nd Symposium on Ruminant Lameness and its Economical Significance on Animal Products. University of Shiraz, Shiraz, Iran; 2013.

7. Schaefer AL, Cook N, Tessaro SV, et al. Early detection and prediction of infection using infrared thermography. Can J Anim Sci. 2004;84(1):73-80. 
8. Hovinen M, Siivonen J, Taponen S, et al. Detection of clinical mastitis with the help of a thermal camera. J Dairy Sci. 2008;91(12):4592-4598.

9. Polat B, Colak A, Cengiz M, et al. Sensitivity and specificity of infrared thermography in detection of subclinical mastitis in dairy cows. J Dairy Sci. 2010;93(8):3525-3532.

10. Martins RF1, do Prado Paim T, de Abreu Cardoso C, et al. Mastitis detection in sheep by infrared thermography. Res Vet Sci. 2013;94(3):722-724.
11. Samara EM, Ayadi M, Aljumaah RS. Feasibility of utilising an infrared-thermographic technique for early detection of subclinical mastitis in dairy camels (Camelus dromedarius). J Dairy Res. 2014;81(1):38-45.

12. Stewart M, Webster J, Schaefer A, et al. Infrared thermography as a non-invasive tool to study animal welfare. Anim Welf. 2005;14(4):319-325. 